\title{
REFLECTING POWER OF TUNGSTEN AND STELLITE
}

By W. W. Coblentz, Associate Physicist, and W. B. Emerson, Laboratory Assistant

\section{INTRODUCTORY STATEMENT}

In a previous paper ${ }^{1}$ it was shown that tungsten, in common with all the pure metals thus far investigated, has a low reflecting power in the visible spectrum, which rises quite abruptly to a high value beyond $2 \mu$ in the infra-red. Unfortunately in assembling the data for publication a smooth curve was drawn through the observations in the region of $0.8 \mu$, on the supposition that the irregularities in the data were due to errors of observation. As a result, an interesting characteristic which has an important bearing upon the production of light escaped attention. This characteristic, as will be shown in the present paper, is a marked depression at $0.8 \mu$ in the reflectivity curve.

In a subsequent investigation ${ }^{2}$ of the radiation from incandescent tungsten filaments the energy curves showed elevations in the smooth curve in the region of $0.8 \mu$ to $0.9 \mu$, which could not be attributed entirely to experimental errors. If tungsten has an indentation in its reflectivity curve, in the region of 0.8 to $0.9 \mu$, similar to the indentations in the reflectivity curves of gold and of copper in the visible spectrum, then selective emission must ocour in this region of the spectrum similar to the selective emission of incandescent gold and copper in the visible spectrum.

A further examination of the spectral reflectivity of tungsten was, therefore, made recently in order to verify these observations. 


\section{APPARATUS AND PROCEDURE}

The apparatus used was a mirror spectrometer, fluorite prism, and a vacuum thermopile of bismuth silver, as described in previous papers. The source of radiation was a Nernst glower, $N$, Fig. I. An image of the glower was projected upon the spectrometer slit, $S$, by means of a concave silvered glass mirror of $50 \mathrm{~cm}$ focal length.

The samples of tungsten examined were in the form of plane mirrors, obtained from the Research Laboratory of the General Electric Co. The surfaces were flat to within less than a wave

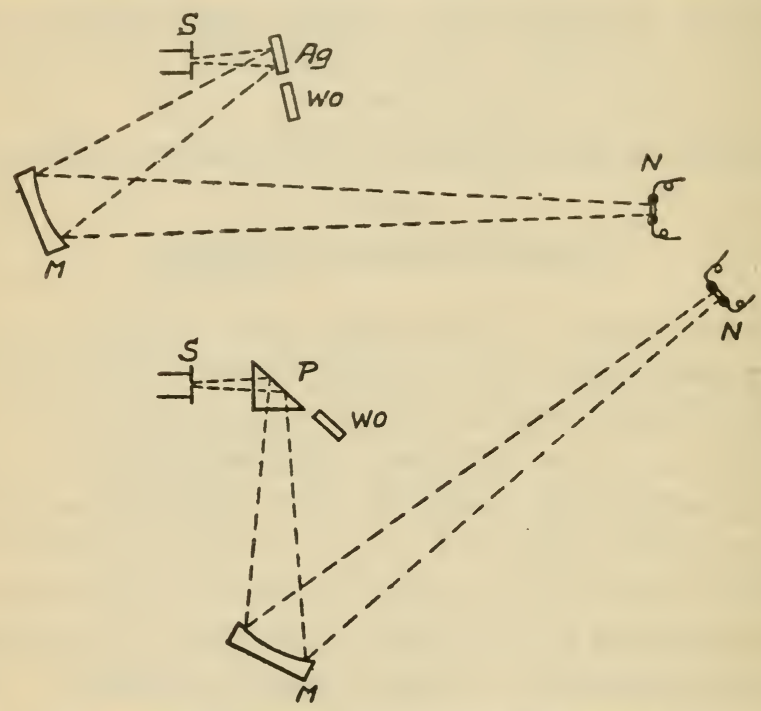

FIG. I.-Apparatus for reflectivity measurements

length of light, and they were highly polished. The reflecting power of the tungsten mirrors was determined by comparison at a small angle of incidence with a freshly silvered glass mirror, $\mathrm{Ag}$, Fig. I, having an optically plane, highly polished surface. These mirrors were mounted upon a slider which permitted interchang ing the samples in the optical path, as described in previous papers.

In order to determine the absolute reflecting power, the observed data were corrected for absorption by the silver mirror. ${ }^{3}$

For the region of the spectrum from $0.5 \mu$ to $I .2 \mu$ the absolute reflectivity of tungsten was determined also by a new method in which the silvered glass mirror was replaced by a right-angled glass prism, $P$, Fig. I. In this arrangement the hypotenuse face 
of the glass prism replaced the reflecting surface of the silvered glass mirror, and hence was in the same plane with the surface of the tungsten mirror which was under investigation, as shown in the lower part of Fig. I. When using this arrangement, the absolute reflectivity of tungsten was obtained by correcting the observed reflectivity for losses by reflection at the surfaces of the right-angled glass prism, the absorption being negligible in the region of 0.5 to $I .2 \mu$.

The change in focus due to change in length of the optical path, caused by the presence of the glass prism was not sufficient to

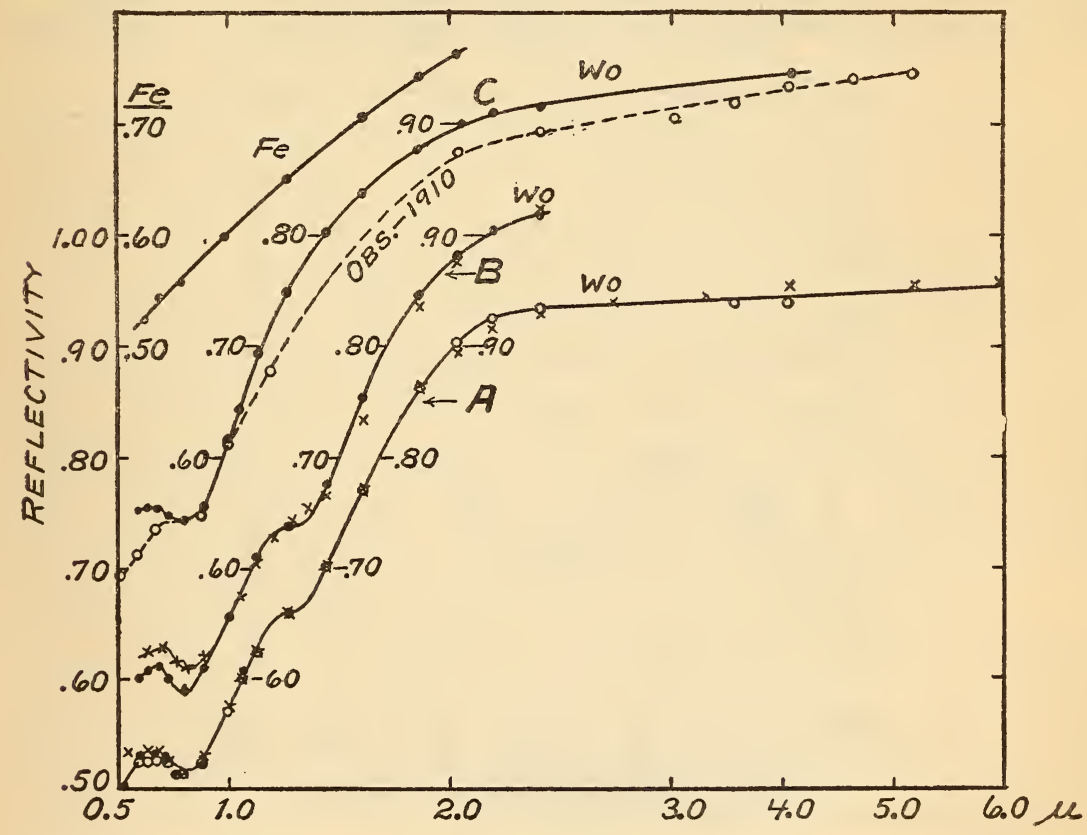

FIG. 2.-Reflecting power of various samples of tungsten

affect the observations by a measurable amount. Hence no attempt was made to have the optical path the same as for the tungsten mirror.

The reflectivity data of tungsten obtained with the rightangled glass prism are in excellent agreement with those obtained by comparison with the silvered mirror.

\section{EXPERIMENTAL DATA}

The experimental data presented in this paper are based upon observations on four samples of tungsten, one of which was examined seven years ago. 
Sample No. I consisted of a tungsten X-ray target, $18 \mathrm{~mm}$ in diameter, mounted in a heavy block of copper. The first measurements, using a silvered glass mirror for comparison, are shown by the circles $(\odot \odot \odot)$ in curve $A$, Figs. 2 and 3 . In order to ascertain whether the indentations in the reflectivity curve of tungsten in the region of 0.8 and $1.3 \mu$ were influenced by the comparison mirror, another silver mirror ${ }^{4}$ was substituted. As shown by the crosses $(x \times \times)$ in curve $A$, Figs. 2 and 3 , the observations are in close agreement with those obtained with the first silvered mirror.

In order to further verify the depression at $0.8 \mu$ in the reflectivity curve, the silvered mirror was replaced by a total reflection glass prism, as illustrated in the lower part of Fig. I. The obser-

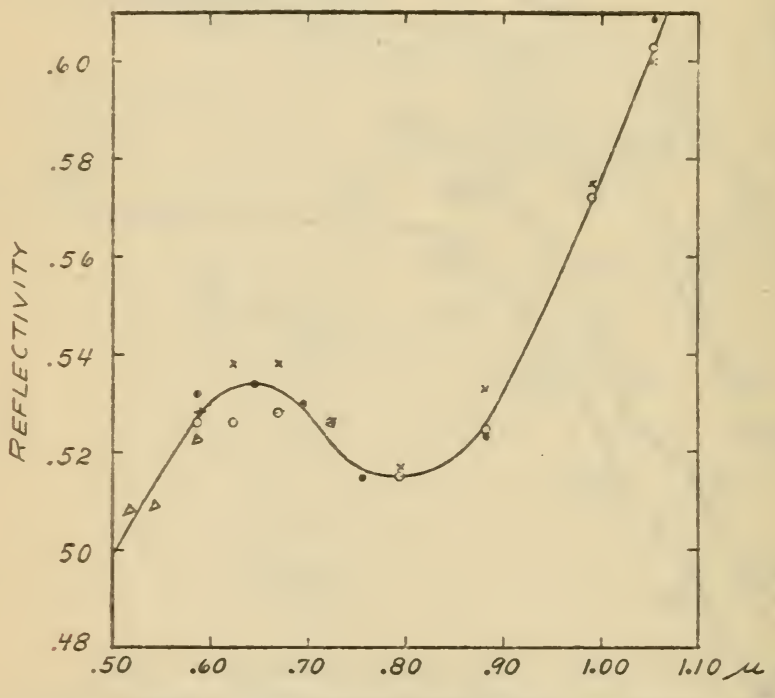

FIG. 3.-Selective reflection of tungsten

vations are in excellent agreement with the preceding observations. These observations are illustrated by the black dots $(\bullet . \bullet)$ in curve $A$, Figs. 2 and 3.

The reflecting-power curve of this sample of tungsten is of interest in showing indentations at $0.8 \mu$ and $\mathrm{I} .3 \mu$. At $5 \mu$ the reflecting power is 95.3 per cent while beyond $6.2 \mu$ it is about 95.8 per cent, which is close to the calculated value obtained from a knowledge of the electrical conductivity of tungsten as shown in the paper just cited. These indentations are of especial interest in view of the fact that this is the first metal yet investigated having reflection minima which occur outside of the visible and the ultra-violet parts of the spectrum. 
Sample No. 2 consisted of a sheet of tungsten, 30 by 14 by 0.5 $\mathrm{mm}$, obtained several years ago. It was flat, but did not seem to take such a high polish as the first sample, owing to its brittleness. The surface showed pits of microscopic size, owing no doubt to the lack of plasticity of the material. This pitting reduces the absolute value of the reflecting power by 2 to 4 per cent, especially in the visible spectrum. The reflecting-power observations, obtained by comparison against silver, are illustrated (by dots; $\bullet .$. ) in curve $B$ of Fig. 2. The depressions at $0.8 \mu$ and $\mathbf{r} .3 \mu$ coincide with those found in the first sample.

Sample No. 3 was the specimen of tungsten examined with a vacuum spectrobolometer seven years ago. ${ }^{5}$ This sample was part of a rod of the metal used in making lamp filaments. A further examination was deemed desirable, in view of the fact that the first observations showed no depression at $\mathrm{I} .3 \mu$ in the reflectivity curve. For this purpose the parallelopiped of tungsten ( 6 by 6 by $22 \mathrm{~mm}$ ) previously examined was cut lengthwise into two pieces, which were cemented side by side upon a glass plate. This formed a wide reflecting surface (dimensions, 22 by i 2 by 2 $\mathrm{mm}$ ) which could be made planer than is possible with a long, narrow surface. The surface, one part of which had been previously examined, was reground and polished. This specimen was not as hard as the first and second samples, and the surface appeared more highly polished and free from minute pits.

The reflecting power is about 55.5 per cent at $0.62 \mu$ to $0.67 \mu$, as compared with a reflectivity of 53.5 in sample No. $x$. As shown in curve $C$, Fig. 2, the reflectivity curve has no indentation at r. $3 \mu$. It is in agreement with the observations of Igro as shown by the dotted curve in Fig. 2. The high reflectivity of this sample of tungsten, at I. $3 \mu$, may be due to the presence of some other metal which is said to be used with the tungsten employed in lamp filaments.

Sample No. 4 was very generously supplied by Dr. Langmuir in reply to our inquiry concerning the purity or the first three samples. The sample No. $\mathrm{I}$ is considered of exceptionally pure material, but in view of the fact that it had not been heated to a very high temperature, it may contain small traces of tungstic oxide.

The present sample was a piece of a rod, 20 by 20 by $8 \mathrm{~mm}$, of tungsten which had been heated in hydrogen nearly to its melting point, thus producing the purest material that has yet been made. 
The reflecting surface had a fairly high polish, but it was not entirely free from fine pits, which seemed to be due to the brittleness and perhaps the structure of the material. This pitting caused a slight scattering of light, thus lowering the absolute values of the reflectivity as compared with sample No. I, which seemed to be more compact and which was quite free from the minute pits present in this sample.

In the region of the spectrum from $0.6 \mu$ to $\mathrm{r} .5 \mu$ the reflectivity was determined by using the glass prism reflecting device, $P$, shown in Fig. I. The observations at I to $I .5 \mu$ were verified and extended to $2.5 \mu$ by comparison with a silver mirror.

The reflectivity data of this sample of tungsten are illustrated by the crosses $(x \times \times)$ in curve $B$, of Fig. 2. They coincide exactly with the measurements on sample No. 2, except in the visible where the reflectivity is somewhat higher, due, no doubt, to a higher polish. It is of interest to note that all these samples of pure tungsten have indentations in common at $0.8 \mu$ and $1.3 \mu$ in the reflectivity curve.

The reflecting power data of pure tungsten are given in Table $\mathrm{I}$. It is to be understood, of course, that these data are average values for the samples examined and that the absolute values for perfect mirrors might be $I$ to 3 per cent higher, especially in the visible spectrum.

TABLE 1

Reflecting Power of Tungsten

\begin{tabular}{|c|c|c|c|c|c|c|c|c|c|c|c|}
\hline $\begin{array}{l}\text { Wave } \\
\text { length }\end{array}$ & $\begin{array}{l}\text { Re- } \\
\text { flec- } \\
\text { tivity }\end{array}$ & $\begin{array}{l}\text { Wave } \\
\text { length }\end{array}$ & $\begin{array}{l}\text { Re- } \\
\text { flec- } \\
\text { tivity }\end{array}$ & $\begin{array}{l}\text { Wave } \\
\text { length }\end{array}$ & $\begin{array}{l}\text { Re- } \\
\text { flec- } \\
\text { tivity }\end{array}$ & $\begin{array}{l}\text { Wave } \\
\text { length }\end{array}$ & $\begin{array}{l}\text { Re- } \\
\text { fec- } \\
\text { tivity }\end{array}$ & $\begin{array}{l}\text { Wave } \\
\text { length }\end{array}$ & $\begin{array}{l}\text { Re- } \\
\text { flec- } \\
\text { tivity }\end{array}$ & $\begin{array}{l}\text { Wave } \\
\text { length }\end{array}$ & $\begin{array}{l}\text { Re- } \\
\text { fec- } \\
\text { tivity }\end{array}$ \\
\hline $\begin{array}{c}\mu \\
0.500\end{array}$ & 0.501 & $\begin{array}{c}\mu \\
0.675\end{array}$ & 0.533 & $\begin{array}{c}\mu \\
0.850\end{array}$ & 0.518 & $\begin{array}{c}\mu \\
1.15\end{array}$ & 0.640 & $\begin{array}{c}\mu \\
1.60\end{array}$ & 0.770 & $\begin{array}{c}\mu \\
2.50\end{array}$ & 0.938 \\
\hline .525 & .508 & .700 & .530 & .875 & .525 & 1.20 & .655 & 1.70 & .810 & 2.75 & .940 \\
\hline .550 & .517 & .725 & .523 & .900 & .533 & 1.25 & .662 & 1.80 & .845 & 3.00 & .943 \\
\hline .575 & .525 & .750 & .518 & .950 & .554 & 1.30 & .665 & 1.90 & .875 & 3. 50 & .945 \\
\hline .600 & .531 & .775 & .516 & 1.00 & .576 & 1.35 & .670 & 2.00 & .900 & 4.00 & . 948 \\
\hline .625 & .534 & .800 & .515 & 1.05 & .604 & 1.40 & .685 & 2.10 & .918 & 5.00 & .953 \\
\hline .650 & .535 & .825 & .516 & 1. 10 & .622 & 1.50 & .726 & 2. 25 & .930 & 6.00 & .958 \\
\hline
\end{tabular}

Sample of Pure Iron.- - In order to obtain a further check on the present data on tungsten, the sample of pure iron previously examined ${ }^{6}$ was reexamined. The surface was not repolished, which no doubt explains the lower absolute reflecting power as 
compared with that previously observed. However, the reflectivity curve is smooth and free from the indentations which occur in the reflectivity curves of tungsten.

\section{PRACTICAL APPIICATIONS}

These data on the reflecting power of tungsten are useful in explaining the irregularities which, as already mentioned, were found in the spectral radiation curves of incandescent tungsten lamp filaments. These irregularities consisted in a spectral energy distribution which is practically a straight line throughout the greater part of the visible spectrum, followed by a marked protuberance at 0.8 to $0.9 \mu$ in the infra-red, or what might be considered a depression at $0.7 \mu$ in the energy curve. The trend of the energy curve was found to be entirely different from that of other metals, e. g., platinum, which had been previouslv investigated.

In the spectral radiation curves previously published the wavelength scale is so small that these irregularities are not very conspicuous. In the present illustration, Fig. 4, the wave-length data are plotted on a large scale, which emphasizes the irregularities under discussion.

In Fig. 4 curve $A$ gives the (relative) energy distribution in the spectrum of a straight wire "hairpin" filament of tungsten in a nitrogen filled bulb, observed three years ago. Curve $B$ gives the spectral distribution of radiation from the outside of the turn of a helical filament of tungsten in a nitrogen-filled lamp. ${ }^{7}$ In these two curves the dotted lines indicate the energy distribution which would be obtained if the reflecting power increased uniformly between $0.7 \mu$ and $\mathrm{I} \mu$, instead of having a depression at $0.8 \mu$.

Curve $C$ gives the spectral distribution of radiation of tungsten computed from the distribution of radiation from a black body at $2200^{\circ} \mathrm{Abs}$., using the reflectivity data given in Fig. 2. The dotted line, as in curves $A$ and $B$, indicates the energy distribution on the basis of a uniformly increasing reflectivity between 0.7 and $x \mu$. This curve is very similar to the observed curves, and it would no doubt fit the observed curves still closer if the exact temperature had been known, and if corrections had been applied for variation of reflectivity with change in temperature. ${ }^{8}$ This would tend to depress the curve at $0.5 \mu$ and make it straighter at $0.55 \mu$ to $0.6 \mu$

\footnotetext{
7 Coblentz, this Bulletin, 14, p. 115; 1917.

${ }^{8}$ Hulburt, Jour. Franklin Inst., 182, p. 695, 1916; Weniger and Pfund, Jour. Franklin Inst., 182, p. 354, I917.
} 
as observed. As a result of this peculiar reflectivity in the visible spectrum, the temperature computed from the slope of the spectralenergy curve is different from that computed from observations in the infra-red, as found in a previous paper. ${ }^{\circ}$

A further application of the reflecting-power data of tungsten is in connection with the question of increasing the luminous efficiency of incandescent lamps. As mentioned in previous papers, one way to increase the luminous efficiency is to obtain a substance having a high reflecting power in the infra-red, a low reflecting power in the visible spectrum, and a high operating

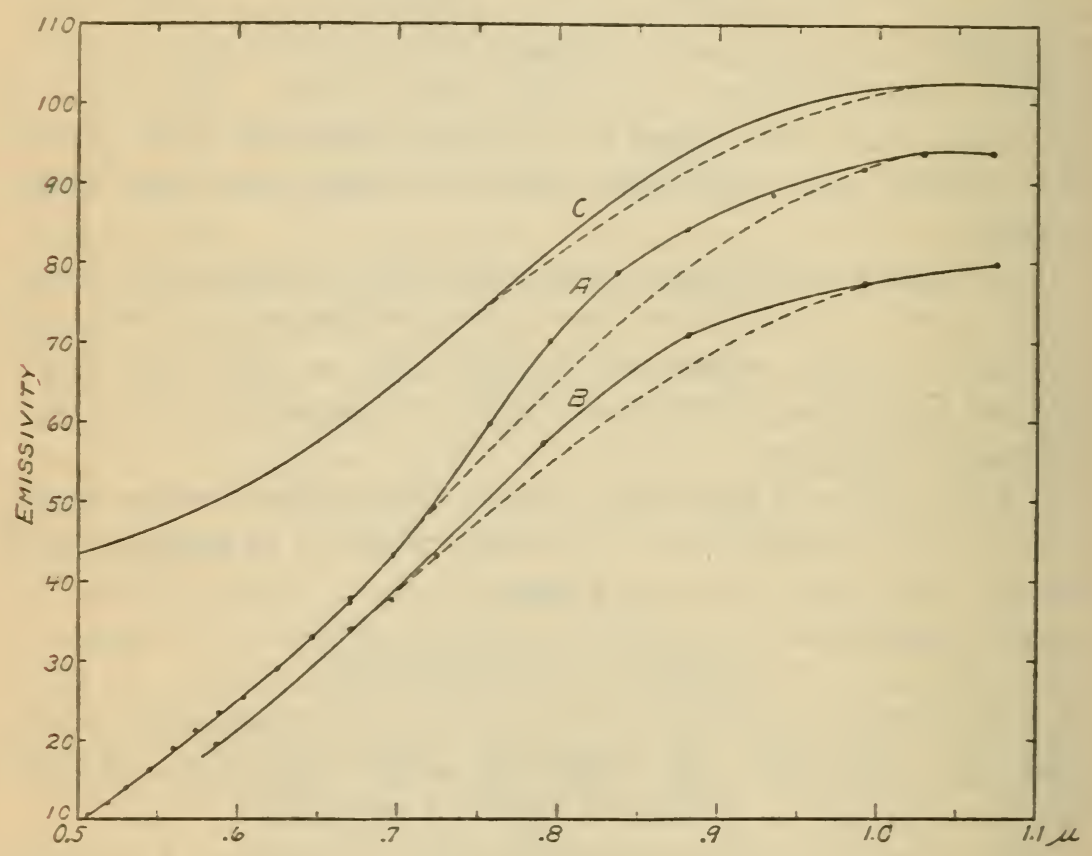

FIG. 4.-Observed (.A and $B)$ and computed $(C)$ spectral radiation of incandescent tungsten

temperature. The reflectivity curves of tungsten indicate that this condition for obtaining high luminous efficiency is fulfilled, to some extent, by using pure tungsten, and that the luminous efficiency of an alloy of tungsten in which the reflectivity minimum at $\mathrm{I} .3 \mu$ is obliterated is still higher than of pure tungsten. Unfortunately, among the contrary things in nature is the reflectivity minimum of tungsten at $0.8 \mu$, which lies just outside the range of the spectrum to which the eye is sensitive, whereas gold with its low melting point has, as is well known, a band of strong selective 
emission in the visible spectrum. If this reflectivity minimum at $0.8 \mu$ in tungsten occurred at 0.55 to $0.60 \mu$ the luminous efficiency would be increased by an appreciable amount.

\section{REFLECTIVITY OF STELLITE}

Stellite is an alloy of chromium, cobalt, and molybdenum. ${ }^{10}$ The sample examined was a plane, highly polished plate 30 by 20 by $5 \mathrm{~mm}$. The reflectivity data given in Table 2 were obtained by comparison with silver. In view of the fact that this material does not deteriorate on exposure to the air, it is applicable for mirrors. It is, therefore, proposed to examine concave mirrors of stellite in order to obtain more accurate data on its absolute reflecting power.

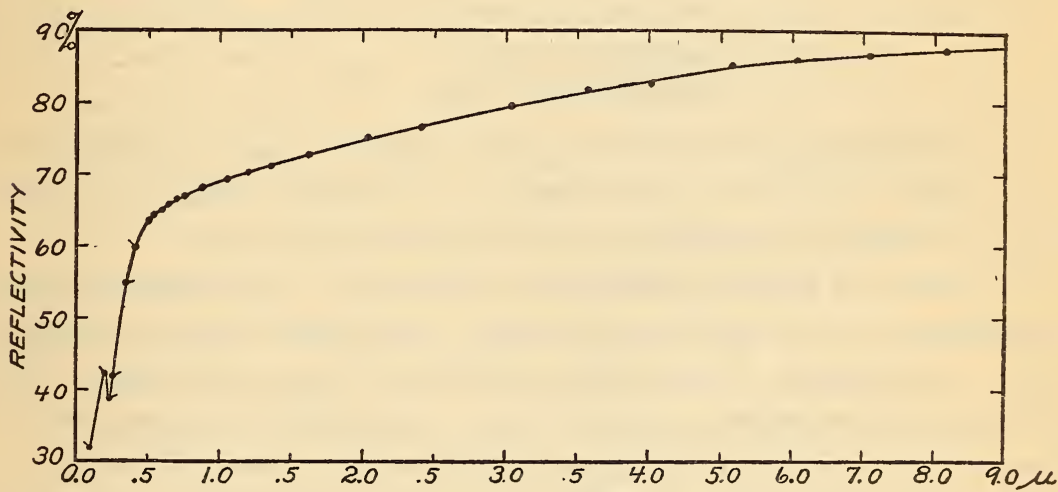

FIG. 5.-Reflectivity of stellite

TABLE 2

Reflecting Power of Stellite

\begin{tabular}{|c|c|c|c|c|c|c|c|c|c|c|c|}
\hline $\begin{array}{l}\text { Wave } \\
\text { length }\end{array}$ & $\begin{array}{l}\text { Re- } \\
\text { flec- } \\
\text { tivity }\end{array}$ & $\begin{array}{l}\text { Wave } \\
\text { length }\end{array}$ & $\begin{array}{l}\mathrm{Re}- \\
\text { flec- } \\
\text { tivity }\end{array}$ & $\begin{array}{l}\text { Wave } \\
\text { length }\end{array}$ & $\begin{array}{l}\text { Re- } \\
\text { flec- } \\
\text { tivity }\end{array}$ & $\begin{array}{l}\text { Wave } \\
\text { length }\end{array}$ & $\begin{array}{l}\text { Re- } \\
\text { flec- } \\
\text { tivity }\end{array}$ & $\begin{array}{l}\text { Wave } \\
\text { length }\end{array}$ & $\begin{array}{l}\mathrm{Re}- \\
\text { flec- } \\
\text { tivity }\end{array}$ & $\begin{array}{l}\text { Wave } \\
\text { length }\end{array}$ & $\begin{array}{l}\mathrm{Re}- \\
\text { flec- } \\
\text { tivity }\end{array}$ \\
\hline $\begin{array}{c}\mu \\
0.15\end{array}$ & 32.0 & $\begin{array}{c}\mu \\
0.45\end{array}$ & 62.0 & $\stackrel{\mu}{\mu}$ & 68.9 & $\begin{array}{c}\mu \\
1.75\end{array}$ & 73.3 & $\begin{array}{c}\mu \\
3.25\end{array}$ & 80.1 & $\begin{array}{l}\mu \\
7.00\end{array}$ & 86.8 \\
\hline .20 & 42.0 & .50 & 63.6 & 1.10 & 69.6 & 2.00 & 74.7 & 3.50 & 81.0 & 8.00 & 87.3 \\
\hline .245 & 39.0 & 1.60 & 65.2 & 1.20 & 70.1 & 2.25 & 76.0 & 4.00 & 82.5 & 9.00 & 88.0 \\
\hline .30 & 50.0 & .70 & 66.5 & 1.30 & 70.9 & 2. 50 & 77.1 & 4. 50 & 83.8 & & \\
\hline .35 & 55.0 & .80 & 67.5 & 1.40 & 71.2 & 2.75 & 78.1 & 5.00 & 84.8 & & \\
\hline .40 & 60.0 & .90 & 68.3 & 1.50 & 71.9 & 3.00 & 79.2 & 6.00 & 86.0 & & \\
\hline
\end{tabular}

The observations on stellite are illustrated in Fig. 5, from which it may be seen that the reflectivity rises abruptly from 30 per cent at $0.15 \mu$ to 65 per cent at $0.6 \mu$, beyond which point the reflectivity 
increases gradually to 87.5 per cent at $8 \mu$. The data for the region from $0.15 \mu$ to $0.4 \mu$ were taken from a paper by Hulburt. ${ }^{11}$ They appear to be an exact continuation of the present observations.

VI. SUMMARY

This paper gives the results of a critical examination of the reflecting power of tungsten in the region of the spectrum from 0.5 to $6.0 \mu$.

The reflecting power of tungsten in the form of plane, highly polished mirrors was determined by comparison with silver and by a new method employing a total reflection prism.

The results obtained are based upon an examination of three samples of pure tungsten and a sample of unknown purity.

All samples show a marked depression in the reflectivity curve at $0.8 \mu$. A similar indentation occurs at $\mathrm{I} .3 \mu$ in the reflectivity of the pure metal, but is absent in a sample of impure tungsten.

The reflecting-power curve of pure tungsten rises abruptly from 50 per cent at $0.5 \mu$ to 90 per cent at $2 \mu$, beyond which the reflectivity increases gradually to about 96 per cent at $6 \mu$.

The bands of selective reflection at $0.8 \mu$ and $\mathrm{i} .3 \mu$ reuder tungsten conspicuous as being the only pure metal thus far investigated which has bands of selective reflection in the infra-red. The minimum of reflection at $0.8 \mu$ causes a perceptible protuberance in the emission spectrum of an incandescent tungsten filament.

The reflection power of stellite rises gradually from 65 per cent at $0.6 \mu$ to 88 per cent at $9 \mu$.

WASHINGTON, March 24, I9I 7. 